\title{
THE PERISSAD LAW.
}

By Major W. R. Livermore, U. S. A.

\section{GENERAL OUTLINE.}

The Perissad Law may be briefly explained as follows:

If the atomic weights of all chemical elements are arranged in a single ascending series, the law of increase is apparently irregular; but almost all of these weights may be so arranged in two parallel series, that each series will show a regular law of increase as far as the atomic weights have been determined, and in almost every instance all of one series fall into those groups of classification of Mendeleyeff that indicate an even quantivalence, and almost all of the others into those indicating an uneven quantivalence.

'This realizes a prediction made by Dr. J. P. Cooke in 1854, as follows :

"The doctrine of triads is, however, as I hope to be able to show in the present memoir, a partial view of this subject, since these triads are only parts of series similar in all respects to the series of homologues of organic chemistry, in which the differences between the atomic weights of the members is a multiple of some whole number."

That paper speaks of the properties of the elements which are functions of the atomic weights, and says that "it does not seem bold theorizing to suppose that the atoms of the members of the same series are formed of a common nucleus, to which has been added one or more groups of atoms, or perhaps one or more single atoms, to which the corresponding element has not been discovered."

At the close of his paper of 1854 Professor Cooke said : "To my conceptions, chemistry will then have become a perfect science, when all substances have been classed in series of homologues, and 
when we can make a table which shall contain, not only every known substance, but also every possible one, and when by means of a few general formulæ we shall be able to express all the properties of matter, so that, when the series of substance and its place in the series are given, we shall be able to calculate, nay predict, its properties with absolute certainty."

Although Cooke and Dumas were then working with a common aim, Dumas was not so confident of this ultimate solution of the problem in hand, for in $185 \%$ he said : "I have often tricd, as Mr. Josiah Cooke has on his part, to compare them, to combine them, and to discuss them with the hope of drawing some conclusion from th $m$ with certainty, but $I$ have been unable to draw from. them anything but doubt. 'The formula deduced from the above simple progression," $(a+n d)$ "would not account for the generation of simple bodies, as Cooke had supposed." Dumas proposed a much more complicated formula, but that of Cooke is so far realized by the perissad law that ont of the 54 elements embraced in the first eight series of Mendeleyeff, the atomic weights of 47 differ from the calculated value by less than three-quarters of a unit, 44 by less than half a unit, 39 by less than a third of a unit, 33 by less than a quarter of a unit, and 23 by less than a tenth of a unit.

When we consider the uncertainty in the determinations of many of those atomic weights that differ most from the regular increase, it may be admitted that Dr. Cooke's prediction has so far been verified that the formula $(a+n d)$ has been proved to lie at the bases of all classifications of atomic weights.

These determinations are not accurate enough to justify any conclusions about the deviations from the regular increase, but in general they appear to be additive in the case of those elements that show the greatest chemical activity, and these deviations may eventually help to determine the character of molecular forces.

The periodic law of Newlands and Mendeleyeff is valuable so far as it asserts that the properties of the elements are periodic functions of their atomic weights, but unsatisfactory and perhaps erroneously stated if it is pushed so far as to assert that the number of elements in each period is identical. 
The Periodic Law has, I think, never afforded any means of predicting the exact atomic weight of a new element, nor has any law been suggested to account for the marked irregularity of the Mendeleyeff series. Newlands in particular has taken great pains to call attention to its jregularity, and most of its strongest advocates believe that there is an exceedingly complex law which regulates this increase. It is the object of this paper to show that the law is exceedingly simple.

\section{ARRANGEMENT OF DATA.}

In tabulating the atomic weights for this discussion it is better to base it upon the lists already published rather than to prepare one for the purpose by weighing the merits of each individual determination. Although the utmost accuracy is not attained by this empirical method, it will at least be free from any coloring, which it is so hard to aroid in comparing the result of observation with the requirements of a law that has already been formulated. In the Journal of Analytical Chemistry, Vol. III. (1889), page 58, in an article by Venable on the atomic weights, four such lists are prepared. Table I of this paper is prepared by taking in each case from the most recent lists, viz., those of Van der Plaats and Ostwald that determination which differs least from the older ones of Clark and of Meyer and Seubert, and taking account of the subsequent determinations that have been reported in the Journal of Analytical Chemistry or in the Chemical News, by taking the mean between the new values and those taken from the lists. The standard in all the tables is $\mathrm{O}=16$.

The new determinations thus considered are as follows:

$\begin{array}{lll}\mathrm{Sn}=119.1 & \text { Bongartz and Classen } & \text { (J. A. C., JII., p. 93). } \\ \mathrm{Zn}=65.37 & \text { Gladstone and Hibbert } & \text { (J. A. C., III., p. 350). } \\ \mathrm{Cr}=52.19 & \text { S. G. Rawson } & \text { (J. A. C., III., p. 350). } \\ \mathrm{Zr}=90.62 & \text { Bailey } & \text { (J. A. C., III., p. 351). } \\ \mathrm{Ru}=101.66 & \text { Joly } & \text { (J. A. C., III., p. 352). } \\ \mathrm{Pd}=106.51 & \text { Keiser } & \text { (J. A. C., III., p. 352). } \\ \mathrm{Mg}=24.29 & \text { Burton and Vorce } & \text { (Am. Chem. J., 12, p. 219). } \\ \mathrm{Cu}=63.59 & \text { T. W. Richards } & \text { (Chem. N., 59, p. 179). }\end{array}$


The determination of the relative atomic weights of hydrogen and oxygen, although it is, perhaps, the most important of all, does not affect this table in consequence of the isolated position of hydrogen.

To adapt the formula $a+n d$ to the series of atomic weights prepared in this manner, take the following values for $a$ and $d$ in the several series of common differences :

\begin{tabular}{|c|c|c|c|c|}
\hline & \multicolumn{2}{|c|}{ First Series. } & \multicolumn{2}{|c|}{ Second Series. } \\
\hline & $a$ & $d$ & $a$ & $d$ \\
\hline $\begin{array}{l}\text { 1st group } \ldots \ldots \\
\text { 2d group } \ldots \ldots \\
\text { 3d group } \ldots \ldots \ldots\end{array}$ & $\begin{array}{r}7.04 \\
65.44 \\
10 \% .80\end{array}$ & $\begin{array}{l}4.01 \\
4.83 \\
6.20\end{array}$ & $\begin{array}{r}12.09 \\
63.30 \\
106.10\end{array}$ & $\begin{array}{l}4.00 \\
4.00 \\
6.29\end{array}$ \\
\hline
\end{tabular}

and let $n$ represent the natural numbers $1,2,3$, etc.

In Table I., column (2) shows the atomic weight, column (3) the difference between the successive terms of (2); columns (4) and (5), two parallel series of numbers in arithmetical progression, each term being placed on the line of that atomic weight which comes nearest to it in value. Column (6) shows the difference between the serial number and the atomic weight (except in the case of $\mathrm{N}, \mathrm{Ni}$ and $\mathrm{Ru}$, which form an independent progression with a common difference between 44 and 45 ; excepting also $\mathrm{Be}$, whose apparent deviation from the law has not yet been explained, and $\mathrm{Ge}, \mathrm{Rh}$, and $\mathrm{Ce}$, whose irregularity may arise from imperfect determinations of their atomic weights). Column ( 7$)$ shows the number of the group in Mendeleyeff's arrangement to which each element belongs.

In Table II. the deviations from the regular increase have been arranged to correspond with the groups and series of Newlands and Mendeleyeff. The last line shows the algebraic sum of the deviations.

Plate I is a graphic representation of the series of atomic weights taken in a single series at (1) and in two parallel series at (2), (3), (4) and (5). At (6) the two parallel series are combined in one, but here the first series is represented by dots and the second series by crosses.

In (5) the asterisks represent the residual series $\mathrm{N}, \mathrm{Ni}$, and $\mathrm{Ru}$. 
COMPARISON OF CALCULATE) AND OBSERVED VALUES.

No regularity and no law is apparent in column (2) of 'Table I., or in line (1) of Plate 1. The differences in (3), Table I., range from 6.43 to 0.40 . The mean of the differences is 2.89 , and we find them distributed about as the theory of probability would lead us to expect from as many numbers scattered at random over the space, subject only to the condition that they should not differ by more than about 6 units from their nearest neighbors, excepting that among the lower numbers the fractions show a slight tendency to favor Prout's law. The average deviation from the mean difference is not far from 1.39 or half of 2.29 .

The regularity of the double series, however, is quite apparent in Plate I., lines (2), (3), (4) and (5), and in (5) it is hard to detect with the eye that there is any irregularity whatever, excepting in the second group of the second series, viz., 63.46, 29.32 , etc. From Column (6) Table I., and from 'Table II., it is seen that the deviations are inconsiderable. Their numerical value would average about .2 , but in the lower numbers less than. 1 . The deviations from the two parallel series are as small as could be expected when it is considered that the four lists from which the table was prepared differ as much from each other as this series differs from the mean of all. The average range of vilues in the four lists would be about .3 of a unit and the new values for eight of the elements above mentioned determined within the past year, differ from those taken from the list by an average of 5 of a unit. These figures are of vital importance in their bearing on the significance of the law, which must not be classed with numerous approximate formula which have been suggested from time to time since the first publication of Dr. Cooke's paper in 1854 . 


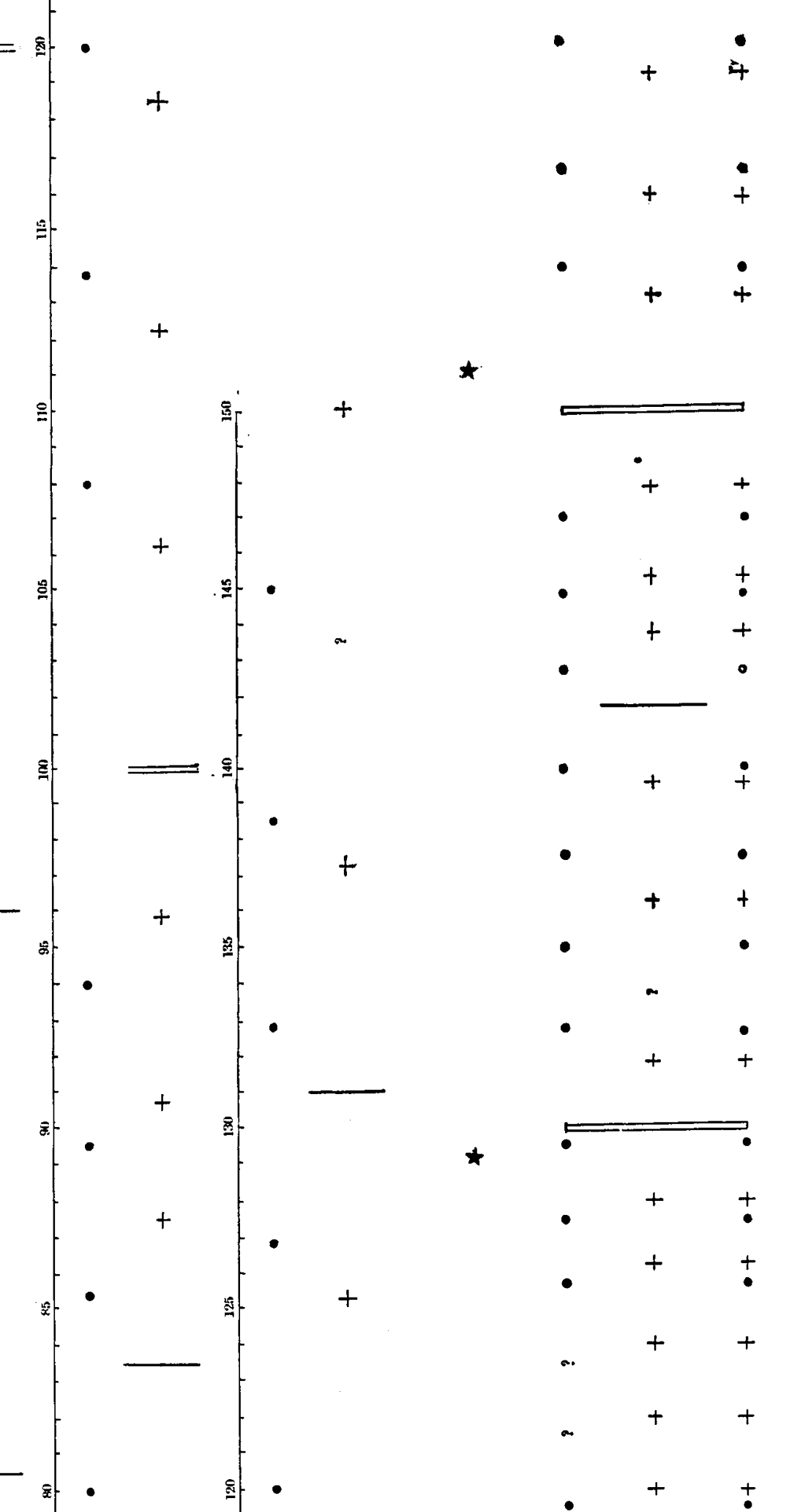





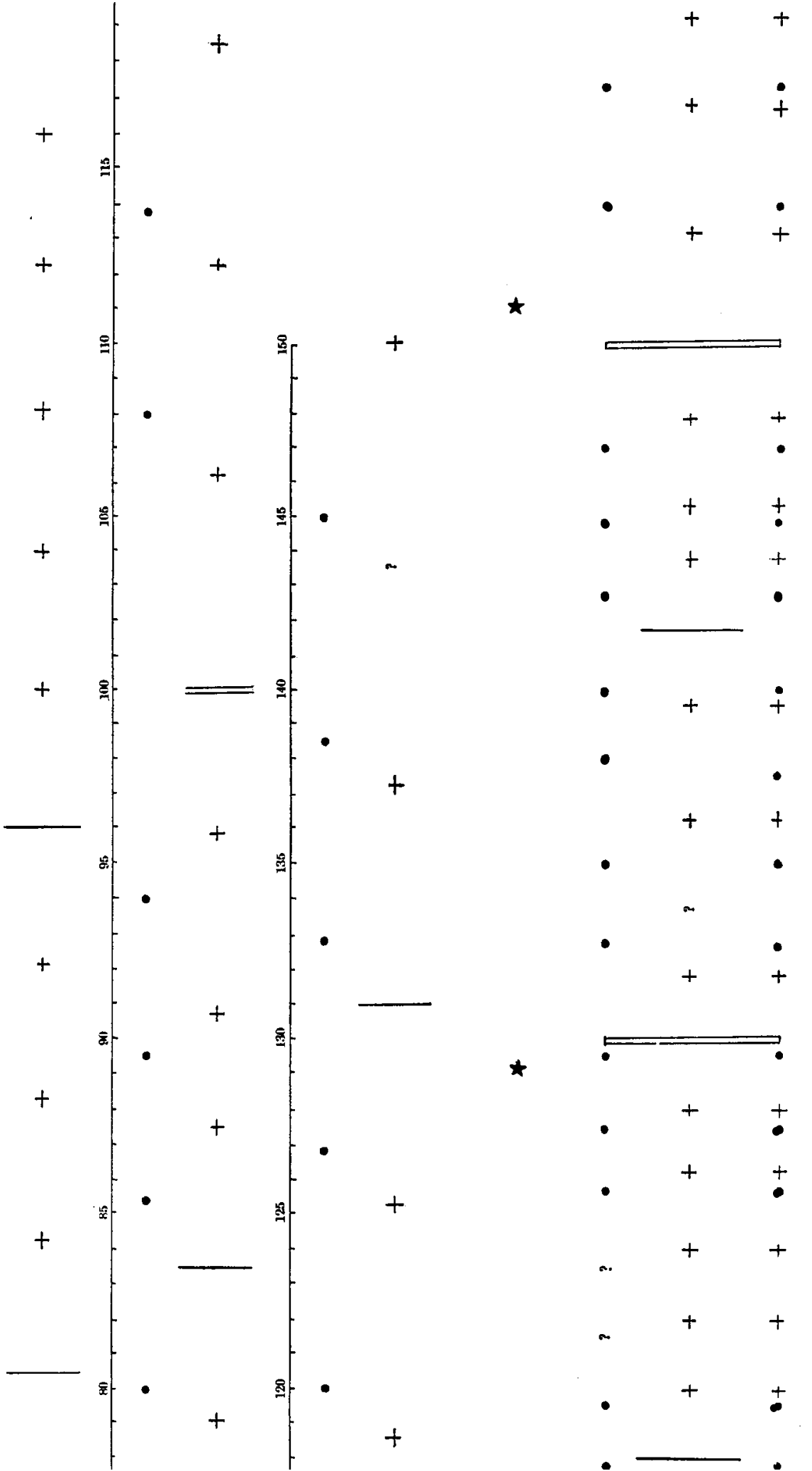



THE PERISSAD LAW.

TABLE I.

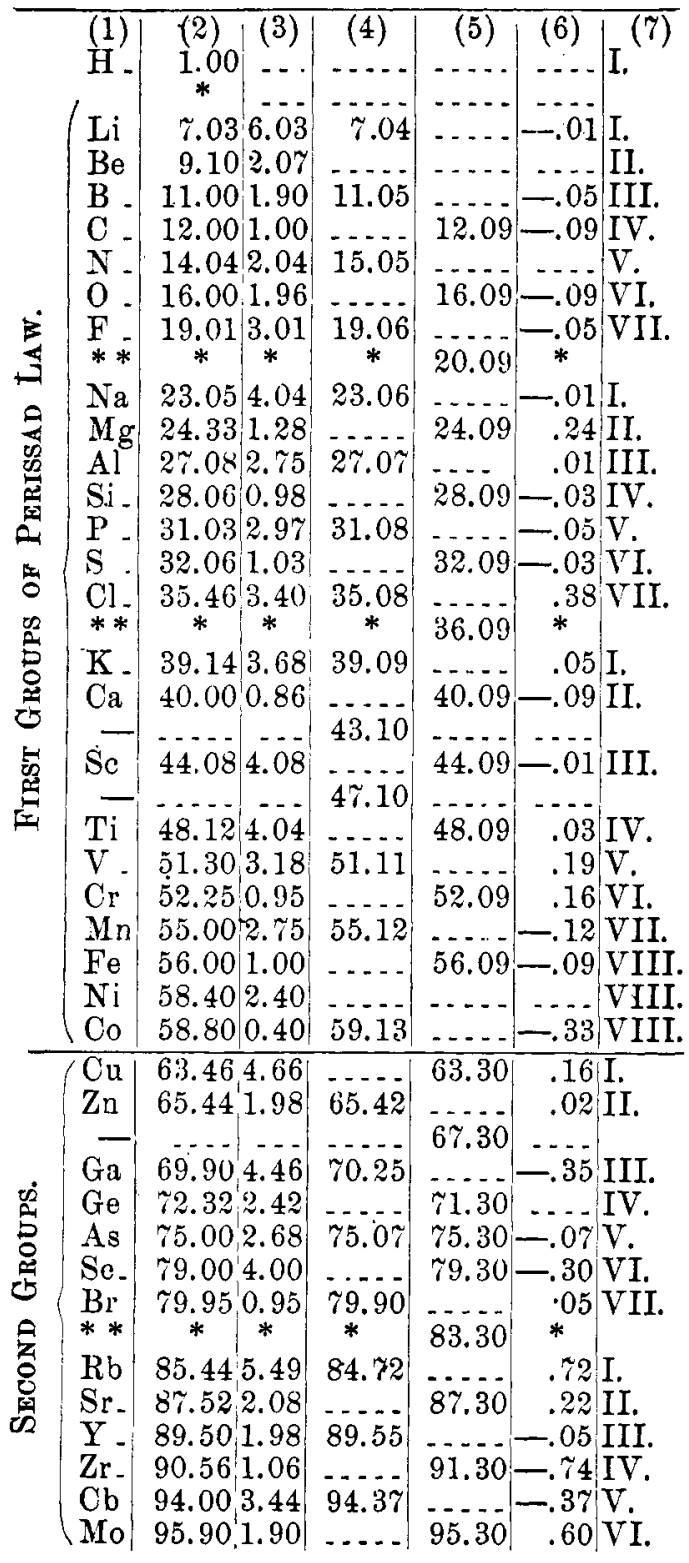


TabLe 1-Continued.

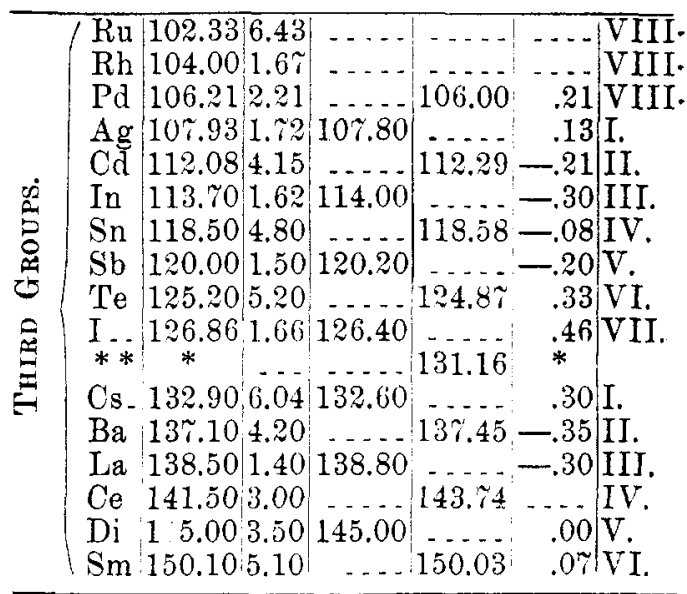

TABLE II.

Deviations.

\begin{tabular}{|c|c|c|c|c|c|c|c|}
\hline $\begin{array}{l}\text { Group } \\
\text { Series. }\end{array}$ & I. & II. & III. & IV. & V. & VI. & VII. \\
\hline 2 & $\overline{-01}$ & & -05 & -09 & & $\overline{-09}$ & -05 \\
\hline 3 & -01 & +24 & +01 & -03 & -05 & -03 & +38 \\
\hline 4 & +05 & -09 & -01 & +03 & +19 & +16 & -12 \\
\hline 5 & $\overline{(+16)}$ & $(-02)$ & $\overline{-35}$ & & $\overline{-0 r}$ & -30 & $\overline{+05}$ \\
\hline . & +72 & +22 & -05 & $-r_{4}$ & -37 & +60 & \\
\hline & +13 & -21 & -30 & -0 & $\overline{-20}$ & $\overline{+33}$ & $\overline{+46}$ \\
\hline $8 \ldots$ & +30 & -35 & -30 & & +00 & +07 & \\
\hline Total. & +19 & $=0 ; 3$ & -15 & $=18$ & -03 & +11 & $F 14$ \\
\hline
\end{tabular}

The groups and series of this table are those of Mendeleyeff's Periodic law. 
For example, L. Meyer (Modern Theories, Eng. trans. p. 162), says: "An examination of the atomic weights of the following groups of elements shows the differences of the atomic weights of their members to be approximately the same.

\begin{tabular}{ccccc}
$\mathrm{Fe}=55.9$ & 47.6 & $\mathrm{Ru}=103.5$ & 95.1 & $\mathrm{Os}=198.6$ \\
$\mathrm{Co}=58.6$ & 45.5 & $\mathrm{Rh}=104.1$ & 88.6 & $\mathrm{Ir}=192.7$ \\
$\mathrm{Ni}=58.6$ & 47.6 & $\mathrm{Pd}=106.2$ & 88.1 & $\mathrm{Pt}=194.3$ \\
$\mathrm{Cu}=63.2$ & 44.5 & $\mathrm{Ag}=107.7$ & 88.5 & $\mathrm{Au}=196.2$ \\
$\mathrm{Zn}=64.9$ & 46.8 & $\mathrm{Cd}=111.7$ & 88.1 & $\mathrm{Hg}=199.8$ \\
$\mathrm{Ga}=69.9$ & 43.5 & $\mathrm{In}=113.4$ & 90.3 & $\mathrm{Tl}=203.7$ \\
- & & $\mathrm{Sn}=117.4$ & 89.0 & $\mathrm{~Pb}=206.4$ \\
$\mathrm{As}=74.9$ & $4 \% .1$ & $\mathrm{Sb}=122.0$ & 88.0 & $\mathrm{Bi}=210.0$ \\
\hline
\end{tabular}

"In the case of osmium, however, its atomic weight appears to be some six or seven units too large, whilst that of indium appeara about two units too small. No conclusion can be drawn as to whether the atomic weight of antimony is 120 , as found by Schneider and confirmed by Cooke, or whether it is 122, as found by Dexter and confirmed by Kessler.

"Although the difference between the atomic weight of arsenic and antimony is 47 when the number 122 is accepted, yet the latest determinations of Cooke show that the number 120 is to be preferred.

"It may, howerer, be safely asserted that should Schneider's number prove to be correct, his determination of the atomic weight of bismuth, viz. $\mathrm{Bi}=20 \% .5$, is probably correct, whilst Dexter's atomic weight of antimony is only adapted to Dumas' atomic weight of bismuth, viz. $\mathrm{Bi}=210 . "$

But these comparisons deal with units rather than with tenths and hundredths. Meyer continues :

"The relations of the differences between the atomic weights justify us in making a selection from different experimental results; still our knowledge is too uncertain to allow of theoretical adjustments of numbers obtained by experiments. There can be no doubt that these differences are subject to law." 
Mendeleyeff, in his Faraday lecture (Jour. Chem. Soc., 55., 641) says:

"In the theory of numbers only do we find problems analogous to ours, and two attempts at expressing the atomic weights of the elements by algebraic formulæ seem to be deserving of attention, although neither of them can be considered a complete theory, nor as promising finally to solve the problem of the Periodic Law. The attempt of E. J. Mills (1886) does not even aspire to attain this end. He considers that all atomic weights can be expressed by a logarithmic function,

$$
15\left(n-0.93 i 5^{t}\right)
$$

in which the variables $n$ and $t$ are $w$ tole numbers."

By this formula the atomic weights of the first 10 elements differ from the calculated ralues by a little less, and the next 20 elements by a little more than numbers selected at random.

Another logarithmic formula is that of Dr. G. J. Stoney. An abstract of his paper published in the Chemical News (5\%., $163,1888)$, and in other periodicals, says that in plotting the atomic weights as ordinates of a diagram, the effort to extract information from the resulting curves was a failure. In plotting their cube roots, however, he found two logarithmic curves with perturbations, which showed distinct laws of increase for perissads and artiads. That for the perissads is expressed as follows :

$$
Y m=k \log \left[a\left(m+\frac{1}{3} \sin \frac{m \pi}{2 i}+\frac{1}{3} \sin \frac{m \pi}{18}+\text { subsequent terms }\right)\right]
$$

the next being probably either $-\frac{1}{2} \sin \frac{m \pi}{9}$, or $-\frac{2}{3} \sin \frac{m \pi}{9}$.

'This is a much more complicated expression than Cooke's origin' al formula $(a+n d)$ which appears to be far more significant in its bearing upon the question of the structure of atoms.

Moreover with all the perturbations, the calculated values do not appear to coincide with the observed values as closely as those of the Perissad Law.

An "Approximate Algebraic expression of the Periodic Law of the Chemical Elements," by Prof. Carnelly, was published in 
the Philosophical Magazine as recently as January, 1890. Prof. Carnelly says : "In 1885 I proposed for the chemical elements the. general formula.

$$
\mathrm{A}_{n} \mathrm{~B}_{2 n}+(2-x)
$$

in which $n$ is the series and $x$ the group to which the element belongs; $\mathrm{A}=12$ and $\mathrm{B}=-2$.

"Since that time, and for the thirteen years previously, I have made frequent attempts to find a simple numerical expression for the Periodic Law, but so far without marked success. Early in the past summer, however, I obtained an expression, which, though only approximate, may still be found of considerable in. terest." This expression takes the form

$$
(6.6 m+\sqrt{v})
$$

in which $m$ denotes the series and $v$ the number of the group of Mendeleyeff's classification.

The deviations from his calculated values range from 0.1 to $6 . \%$. Their mean value is 1.9 , and 33 out of 54 are greater than unity,

The Rev. Dr. Haughton has perhaps done as much as any one to call attention to this important problem of representing the relation of atomic weights by algebraic expressions, and his well known geometric illustrations cannot fail to be both interesting and instructive to students of chemistry and mathematics.

Dr. Haughton calls attention to the constant increase of the artiad series from $\mathrm{C}$ to $\mathrm{Si}$ by locating them upon the same straight line in his diagram, which also shows the break in the series between $\mathrm{O}$ and $\mathrm{Mg}$ where his straight line crosses the axis.

\section{RESULTS OF COMPARISON.}

Referring to column ( $\tilde{F})$ Table 1 showing the group in the Hendeleyeff series to which the element belongs and bearing in mind that Groups I., III., V. and VII. of this series correspond to the perissads and II., IV., VI. and VIII. to the artiads, it appears that all of the first series of regular increase are perissaus except $\mathrm{Co}$ and $\mathrm{Zn}$, and all of the second series are artiads except $\mathrm{Sc}$ and $\mathrm{Cu}$ of these, $\mathrm{Cu}$ and $\mathrm{Zn}$ are connecting links between the first and second groups.

Co perhaps belongs to another series, and Sc is little known. 
The first groups of the first and second series have the common difference of 4.01 and 4.00 respectively. Their first terms are 7.04 and 12.09. Hence it follows that the difference between any term of the first series and the next term of the second should be about a unit. This is true for seven couples, and only fails where a term is missing from one of the series. In the same manner the difference between any term in the third group of the second series and the next term of the first series should be about one and a half units. Nothing can be predicted about the relation between the second groups owing to the irregularity of the second series in that group.

Comparing the second series column (5) Table 1 with the last of atomic weights in column (2) we find no element corresjonding to the terms $20.09,36.09,83.30$ and 131.16 , nor is it probable that an element will be discovered with an atomic weight corresponding to these numbars, for the reason that they occur at that place in the series where the change from electro-negative to electropositive occurs.

No element corresponds with 63.30 , but the second group of the second series to which this term belongs is so irregular that it would be unsafe to base any prediction upon the common difference assumed for this series. Hore accurate determinations of some of the atomic weights of this group are much to be desired.

If praseodymium maintains its claim to a place in the series with an atomic weight of 143.6 , it corresponds with the term 143.5 better than cerium.

The determination $\mathrm{Sc}=44.08$ brings it in the second series with the artiads, al though it is regarded as a triad. It is not impossible that subsequent determinations may find a value nearer to 43.10 , its calculated place in the first series. If philippium has a place in the series it should lie between 45 and $48^{*}$ and perhaps correspond to $4 \% 10$, leaving 44 or 43 for some other element. If it can be demonstrated that any other atomic weight than that of scandium lies between 40 and 48 , the law of the octaves will have to be stated in broader terms than heretofore.

\footnotetext{
* Crooke's Researches on the Rare Earths, Chem. News, 60, 28.
} 
The Perissad law would thus hold true if two more elements were inserted in the fourth series of Mendeleyeff than are provided for therein.

Whether the eighth group of Mendeleyeff should be associated with that group of common differences which precedes or with that which follows it, remains to be determined. It is also uncertain whether terms will ever be found between the several groups of constant increase near the atomic weights, 60 and 100.

The position of tellurium in the series has always been unsatisfactory. The old value was about 128 , which is greater than that of iodine, whereas analogy would make it less.

Brauner has worked hard to find the true value. He is not yet satisfied with his results, and asks his brother chemists to leave the problem to be worked out by him. (Jour. Chem. Soc., 55, 411-July, 1889.)

He says: "According to the recent determinations made by $\mathrm{J}$. P. Cooke as well as those of Stas, these elements have the following atomic weights, $\mathrm{S} b=119.96$ and $\mathrm{I}=126.86$, and we may therefore expect that the atomic weight of tellurium will be still smaller than 125, namely, about 123.5."

This is only another illustration of the fact that the Periodic law furnishes no guide whatever to determine the exact value of atomic weights. The Perissad law would give the following value for tellurium, viz.: $124.8 \gamma+.11=124.98$. This value depends, however, upon that of the other six elements in the third group of the second series, which are not as well known as those of the first groups.

\section{INFERENCES.}

The deviations from regular increase cannot be expected to correspond in every case with the chemical and physical properties, and in the present state of knowledge it would be impossible to form any conclusion from such comparisons, which, nevertheless, are valuable in the way of suggestion.

Table II. shows that in groups I. and VII. of the Mendeleyeff classification, the atomic weights found by observation are on an average in excess of those obtained by calculation. 
In a general way the elements whose deviations are positive are chemically active, readibly fusible, strongly electro-positive or electro-negative, and have the greatest atomic volumes. On the other hand those whose deviations are negative, are chemically and electrically neutral, are fusible only with great difficulty, and have small atomic volumes.

The general bearing of the Perissad Law upon the structure of atoms cannot be stated in better terms than those of Dr. Cooke, quoted at the beginning of this paper, viz.: "that the atoms of the members of the same series are formed of a common nueleus, to which has been added one or more groups of atoms, or perhaps one or more single atoms to which the corresponding element has not been discovered."

The law has been suggested to the writer of this paper as follows:

A mathematical aualysis of molecular forces shows that if gravitation is the controlling force at minute as well as at sensible distances, then it must follow that the particles of which an atom is composed are to a great extent arranged in lines and not scattered promiscuously nor homogeneously through the space occupied by the atom. In other words matter must be fibrous or reticular, having a skeleton or frame work which holds together the mass, which is perhaps surrounded by an atmosphere of ether. 'This supposition is not so improbable as to be dismissed without due investigation. If the skeleton is composed of particles in rapid motion, in orbits nearly rectilinear, and if the surrounding ether is of a discontinuous nature and also in rapid motion, these motions are sufficient to counterbalance the tendency to collapse due to the force of attraction.

Whether this or any other of the assumptions about the constitution of matter be true, both the Perissad and the Periodic Law have an important bearing upon the problem.

Whatever opinion may be held with regard to the genesis of chemical atoms there can be no question that the masses vary according to some law.

Perhaps, for instance, an atom of aluminium has been formed by the addition to an atom of sodium of one or more other particles having a weight of four, perhaps by addition to one of magnesium 
of a weight of three, or to one of boron of a weight of sixteen; perhaps on the other hand an atom of sodium has been formed by the loss of a weight of four from one of aluminum, etc. In all these cases the structure may be regarded as the same, and the phenomena may be investigated by treating a heavier atom as composed of a lighter one with something added to it. The above supposition, however, is at variance with that which assumes that the several atoms are composed of essentially different substances. The question of the constitution of matter is one of rital importance to the science of chemistry and can only be solved by a systematic course of investigations. On this point Victor Meyer in his address at Heidelberg, Sept. 18 1889, says :

" Has it not been in our own day that the most prominent orator amongst German' naturalists, one who astonishes us by the comprehensiveness of his knowledge, has adopted as his own Kant's judgment on chemistry, namely, that 'chemistry is a science, but not a science in the highest sense of the word, that is, a knowledge of nature, reducerl to mathematical mechanics.' ***

"If, without question, it is the aim of all natural science to understand phenomena so fully that they may be describedin a mathematical form and, as far as they are unknown, may be predicted, a science which is so far distant from this aim as to look merely for the path that shall some day lead to it, must be considered as in its infancy. In the present stage our way of thinking and acting has this peculiarity. *** Before we can arrive at a mathematico-physical treatment of chemical phenomena in general, two fundamental problems must be solved; an hypothesis which allows a control by experiment (even within the same limits which to this day are imposed upon physics in regard to the law of gravitation), must answer these questions:- What is Chemical Affinity? and what is Valency?"

Two paths are presented and each should be pursued until it leads to an improbable conclusion, or furnishes a further clue to the solution of the problem.

The first path above mentioned appears far more promising, and the bearing of the Periodic and Perissad Laws upon this problem can be explained by a general illustration as follows: 


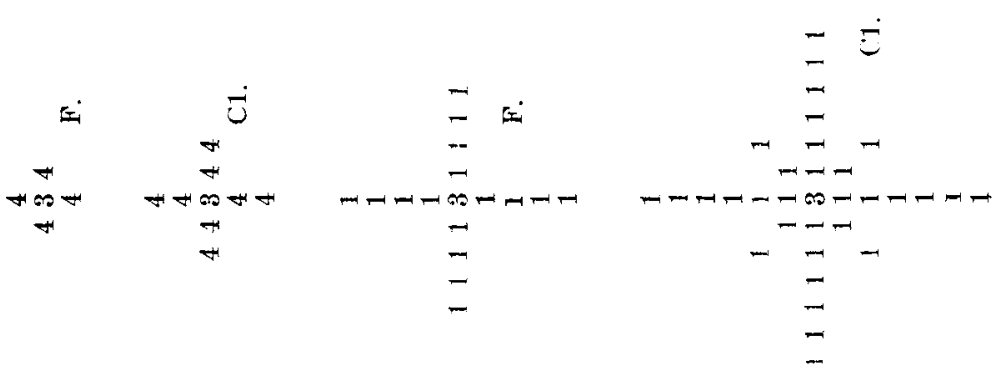

焉
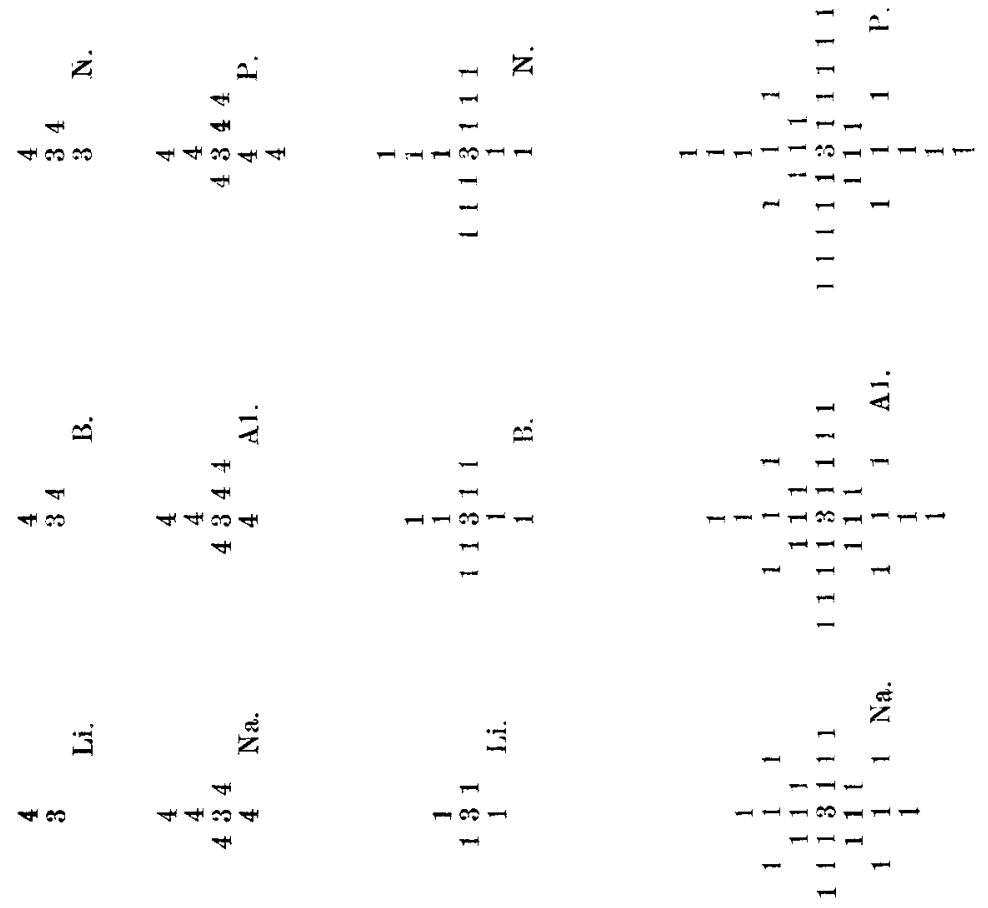

Suppose the atom to be composed of a framework with an envelope of ether, and represent the structure upon a plane surface simply for the convenience of illustration.

According to one interpretation of the Perissad Law the atoms of the first group of the first series have been formed from a nucleus of 3 by the addition to it $1,2,4,5,6,7,8,9,12,13$ and 14 times of particles having a weight of about 4 , and the other groups and series in similar manner.

These increments may have been added to all the extremities up to a certain point and then they may have formed around other points of the atom, or the whole increment may have united to one extremity, the next to another, etc., as shown in Plate II. In the case of elements whose deviations are additive, the excess over the regular increase may be referred to the greater amount of ether associated with the corresponding atoms.

By alsother interpretation of the Perissad Law of regular increase an artiad atom may have been formed by the addition of 1 to a perissad, then a perissad by the addition of 3 to an artiad, etc., as shown in Plate III. These diagrams suggest answers to the questions, What is Chemical Affnity, what is Valency?

Remsen (Theoretical Chem., 188\%, p. 28\%) savs of Chemical Affinity :

"We know that when hydrogen and chlorine are brought together they combine with a great evolution of heat. *** The phenomenon suggests such phenomena of attraction as those of gravitation, electricity and magnetism. We, therefore, picture to ourselves the atoms of hydrogen and chlorine as drawn together by an attractive force, much as the stone thrown upwards is drawn to the earth or as the electrified body is attracted by other bodies. In each case to separate the attracted substances an expenditure of energy is necessary. Without any conception in regard to the nature of this chemical force we may for convenience call it chemical affinity. The first object in view in the study of this force is to measure its intensity in different cases. What is the difference between the attraction exerted between hydrogen and chlurine and that exerted by hydrogen and oxygen, etc., etc.? Is it dependent upon the nature of the substance, or is it independent of the nature and only dependent on the mass?" 
If the path upon which we have set out proves to be the correct one, it will probably lead to the conclusion that the attractive force is not only similar to but identical with gravitation. The arrangement of the particles in lines increases the intensity more than enough to make up for the small masses as compared with the masses of sensible objects. Atomic repuision is culsed by the kinetic energy or contrifugal force of ether, of which the atoms are composed, and with which they are surrounded; but when they are brought together by external pressure upon the masses or by a loss of heat and diminution of the repulsive forces, the skeletons come within the spheres of their mutual attructions and the union takes place. If the ether is more condensed around the lines forming the skeleton and if it revolves around these lines as axes, the chemical and electrical conduct of the atom may depend upon what part of the skeleton projects so far as to influence the neighboring a toms.

Valency may be described as follows: If we refer the repulsive force produced by the motion of the ether to equipotential surfaces, we may say that a monad atom has one point projecting beyond one of these surfaces, a dyad atom two points, etc. 'I'he difference between an electro-positive and electro-negative atom may depend upon the direction in which the ether revolves as suggested by the theory of Ampere or by the fact that one atom exposes a re-entrunt to another's salient, as suggested by 'Table III. Dl. Asche also refers to this combination in a paper on Didymium, read before the British Association in 188\%. In the last line of Table III. the electro-positive and negative bonds are expressed by + and - respectively. Much is known and much remains to be known about the position of these bonds in space. The diagram on a plane surface is so generally employed in chemistry that no misapprehension can arise from this form of illustration. 